\title{
Structural Efficiency of Composite Struts for Aerospace Applications
}

\author{
Dawn C. Jegley ${ }^{*}$ and K. Chauncey $\mathrm{Wu}^{\dagger}$ \\ NASA Langley Research Center, Hampton, VA 23681 \\ James E. Phelps ${ }^{\star}$ and Martin J. McKenney* \\ ATK Space Systems Inc., Hampton VA, 23681 \\ and \\ Leonard Oremont ${ }^{\S}$ \\ Lockheed Martin Corp., Hampton VA, 23681
}

\begin{abstract}
The structural efficiency of carbon-epoxy tapered struts is considered through trade studies, detailed analysis, manufacturing and experimentation. Since some of the lunar lander struts are more highly loaded than struts used in applications such as satellites and telescopes, the primary focus of the effort is on these highly loaded struts. Lunar lander requirements include that the strut has to be tapered on both ends, complicating the design and limiting the manufacturing process. Optimal stacking sequences, geometries, and materials are determined and the sensitivity of the strut weight to each parameter is evaluated. The trade study results indicate that the most efficient carbon-epoxy struts are 30 percent lighter than the most efficient aluminum-lithium struts. Structurally efficient, highly loaded struts were fabricated and loaded in tension and compression to determine if they met the design requirements and to verify the accuracy of the analyses. Experimental evaluation of some of these struts demonstrated that they could meet the greatest Altair loading requirements in both tension and compression. These results could be applied to other vehicles requiring struts with high loading and light weight.
\end{abstract}

\section{Introduction}

NASA evaluates the efficiency of structural concepts for aircraft and spacecraft components with the goal of designing lightweight parts. Currently NASA is interested in structurally efficient truss structures for application to spacecraft and aircraft components such as supports for antennae or solar panels, lunar lander struts, components for use on the lunar surface, strut-braced wing components, aircraft spars or unmanned aerial vehicles.

Structural efficiency is defined here as the ratio of a structure's load-carrying ability to its mass. Studies involving the structural efficiency of shells date back to the NACA days and are continued into aircraft design today ${ }^{1-7}$ The study of composite struts to be described in this paper summarizes a 2.5 -year effort involving NASA and industry partners.

One candidate for weight savings through the use of composites is the Altair lunar lander. The Altair project is one element of NASA's Constellation program, which is intended to return human's to the Moon within approximately the next 10-15 years. Composite materials and non-traditional designs offer opportunities for reduced mass compared to conventional aluminum tubes with a uniform circular cross section. The current Altair lunar lander point-of-departure design consists of a truss-based descent module composed of a large number of truss members $^{8}$ as shown in Fig. 1. The lander truss serves as the support structure for the liquid oxygen and liquid hydrogen propellant tanks, and for up to eighteen metric tons of payload mass (mounted on the top of the lander).

\footnotetext{
${ }^{*}$ Senior Aerospace Engineer, Associate Fellow, AIAA, Structural Mechanics and Concepts Branch, mail stop 190.

${ }^{\dagger}$ Senior Aerospace Engineer, Structural Mechanics and Concepts Branch, mail stop 190.

* Senior Aerospace Engineer, Structural Dynamics Branch, mail stop 230.

$\S$ Senior Aerospace Engineer, Structural Mechanics and Concepts Branch, mail stop 460.
} 
The current lunar lander is significantly more massive than the lunar lander of the Apollo program, and therefore presents new and different design opportunities. Because of the need to reduce mass, the lander truss elements must be designed to operate at maximum structural efficiency. The use of composite struts to directly carry propellant and payload induced launch loads is generally speaking unique. Long struts have been evaluated in the context of deployable parts of a space station, telescope elements, and solar panels. In general, these applications require precise positioning but carry little load and tend to be driven by stiffness rather then strength requirements. In contrast, some of the struts for Altair must carry loads greater than $100,000 \mathrm{lb}^{8}{ }^{8}$ Therefore, the primary focus of this study is highly loaded struts. Because the lander struts are highly loaded in compression during launch and ascent, there are a variety of unique and critical design parameters affecting the optimum design.

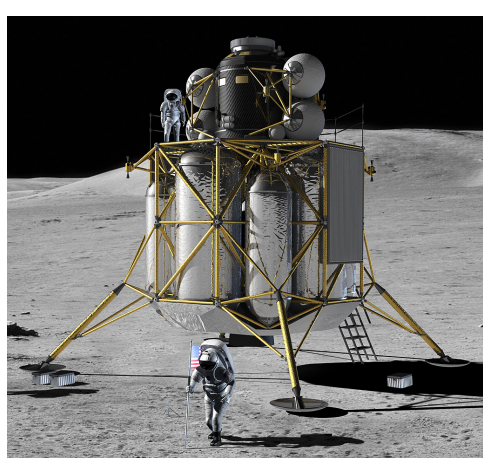

Figure 1. Altair lunar lander.

It is noted here that as of the time of this writing NASA's plans that were part of the Constellation program (including Altair) are undergoing significant change. NASA is considering alternative missions to a lunar return. The studies carried out here however have broad applicability to any aerospace vehicle using a strut-based design, where the struts are likely to carry high compressive loads.

\section{Preliminary Industry Studies}

Under contract to NASA, preliminary trade studies were preformed by Lockheed Martin, ${ }^{9}$ Boeing ${ }^{10}$ and Northrop Grumman ${ }^{11}$ to determine optimum designs for specific length-load combinations. These studies resulted in both optimal point designs and demonstrations of trends such as when buckling was the critical load condition, when one fiber system or stacking sequence was preferable over another and how the strut diameter and length were related to load carrying ability. In addition to the trade studies, the goals of these initial contracts were to determine the state of the art in strut design and fabrication and to guide future NASA research. Each contractor fabricated manufacturing demonstration articles to show the methods of construction. Some of these manufacturing demonstration articles were deemed of high enough quality to use as test articles. Based on these studies, two concepts were selected for further evaluation including additional trade studies, detailed design, fabrication, and testing.

\section{Lunar Lander Strut Structural Requirements}

The early design stages of the Altair lunar lander led to some basic requirements that were used in the present trade study and analysis. The length and corresponding load of over 200 struts in 30 strut groups in the current lunar lander design were considered for this study. Struts within a group share common lengths and load carrying requirements. These requirements included compression loads up to $107,585 \mathrm{lb}$ and tension loads as high at 60,182 $\mathrm{lb}$ and for struts having lengths ranging from 53 to $135 \mathrm{in}$. While multiple struts meet at each node in the baseline lander design, the geometric restrictions on the design are based on the worst case of 11 struts connected to one node. Ideally the struts would be pinned at the nodes, so pinned end conditions were assumed on all ends. In addition, since assuming pinned conditions would result in the minimum buckling load for each strut, this assumption is conservative. The load and length requirements of the 30 strut groups considered in these studies are presented in reference 8 and specify Design Ultimate Loads (DUL) in tension and compression with a 1.4 safety factor already included.

Struts were required to withstand the design loads without buckling in either a global or local mode, not to exceed stress or strain allowables, and not to have any natural frequencies less than $15 \mathrm{~Hz}$. Temperature effects were assumed to be negligible since the lunar lander would not be subjected to temperature extremes at launch, which is when the maximum mechanical loads occur. It is also assumed that the lander would be protected from impact damage both during assembly and on the launch pad so reduced properties to allow for improved damage tolerance have not yet been considered by the Altair project. No minimum stiffness value was identified as a design requirement. 


\section{Trade Study}

After considering the results from the initial industry studies, new contracts were awarded to consider a wider range of strut geometries and requirements. Two contracts were awarded to complete the trade study examining designs for the 30 strut groups and to fabricate representative struts meeting the highest compressive load requirement. In order to conduct the trade study, different fibers, stacking sequences, material allowables and strut geometries were considered and their influence on the strut assembly weight was evaluated. Metal fittings are required to connect the struts to the nodes in the assembly so the metal fitting and the fitting-composite interface were included in the study. The fittings can have a significant effect on the mass of the strut assembly. Boeing's studies used a large-diameter fitting which would be bonded to a uniform-diameter composite section while Northrop Grumman's studies used a small-diameter fitting with corrugations so that the connections to the composite were not as dependent upon an adhesive bond. These metal fitting concepts are described in subsequent sections.

Ultimately the total weight of all strut-node assemblies is the weight that matters in launching the vehicle. Each contractor evaluated and optimized the 30 strut-group designs and summed the weights of each, multiplied by the number of struts in each group. Fittings were sized to meet the loading requirements of each strut. For purposes of the trade study, the composite body taper was 4 degrees in the Northrop Grumman struts (with no taper in the fitting) and the fitting taper was 22 degrees in the Boeing struts (with no taper in the composite body). These optimal results are discussed by examining the sensitivity to each design parameter. The design methodology used and more results of the trade studies, are presented in references 12-13. Three types of fibers, low-modulus AS4, intermediate-modulus IM7, and high-modulus M55J, were considered to determine the impact of fiber stiffness and strength on strut weight. The weights for the optimized strut assemblies were normalized by the weight of aluminum-lithium struts calculated in the same manner as the weights for IM7 and M55J struts and are shown in Fig. 2. The total optimum weight for the aluminum-lithium strut assemblies is $2002 \mathrm{lb}$. AS4 is not included in the figure since it was not the optimum material in any case. Filled bars represent design with pristine properties (in which material allowables assume no damage) while cross-hatched bars represent design with damage tolerant properties. Red bars represent Northrop Grumman's corrugated fitting struts and blue bars represent Boeing's bonded fitting struts. The optimum weights determined using different methods and assuming different end fittings are within two percent of each other and are approximately 30 percent less than for aluminum-lithium struts, assuming pristine properties. If only one fiber system is to be used, then IM7 is the optimal choice. A small amount of additional weight could be saved if a few struts were made from M55J with the remaining made from IM7. This complication may not be practical but could be considered.

The studies were first conducted assuming that the struts would not be subjected to non-visible impact damage in the manufacturing and assembly environment. However, this assumption may be modified in the future so an evaluation of the sensitivity of the strut mass to minimal damage was conducted. A comparison was made between using designs based on "pristine" properties and "notched" allowables which assumes the strut maintains its required load-carrying ability with some damage. The consequence of using notched allowables to account for impact damage possibilities rather than pristine allowables can increase the weight of the total system by up to $10 \%$ when the intermediate stiffness fiber, IM7, is used, as shown in Fig. 2. An even larger weight penalty may result if M55J fibers are used since the M55J system is less damage tolerant that the IM7 system. No assessment of the damage tolerance of aluminum-lithium struts was conducted.

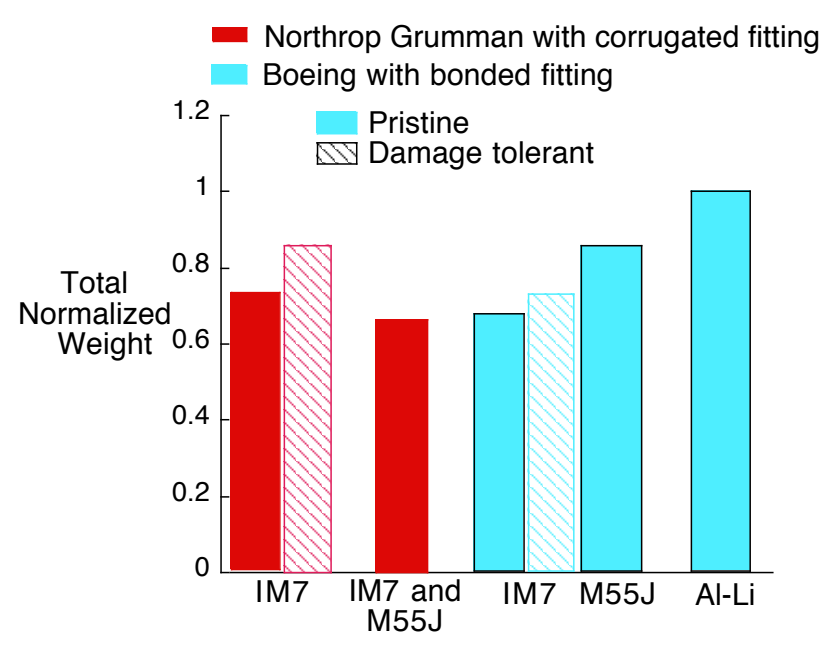

Figure 2. Total strut weight for optimal struts. 


\section{Detail Design and Optimization}

In addition to an evaluation of the struts in total, a detailed design of the most highly loaded strut was determined. This strut is $83.66 \mathrm{in}$. long, and is required to support $107,585 \mathrm{lb}$ in compression and $60,000 \mathrm{lb}$ in tension. Stacking sequences, strut body geometry, material, damage tolerance requirements, initial geometric imperfections, taper and fitting geometry were considered. Key findings of this study include the relative insensitivity of weight to small changes in diameter, and the significant effect on weight found by varying stacking sequence, as shown in Fig. 3. The ideal strut body diameter is approximately 6 inches and the ideal stacking sequence has approximately 63 percent 0 -degree plies, 25 percent \pm 45 -degree plies and 12 percent 90 degree plies. 0 degrees is along the axial direction of the strut. Note that the optimal strut with the laminate with only 0 degree plies is almost the same weight as the ones with 10 and 20 percent \pm 45 degree plies, indicating that the \pm 45 degree plies do not significantly reduce the structural efficiency. Typical

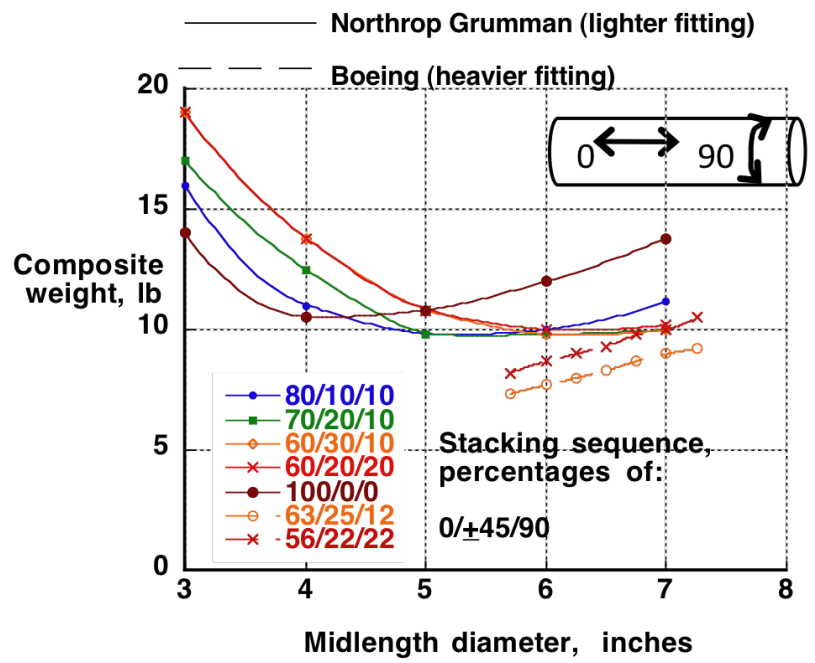

Figure 3. Optimal stacking sequence and diameter of the most highly loaded strut.

design methodologies require off-axis lies to assist in off-axis loading and damage tolerance, so the \pm 45 degree pies were included in this study. Other ply orientations were not considered in this study. In order to achieve a 6-inch diameter at the strut center, a taper is required at each end to allow multiple struts to joint together at one node. Varying the taper angle for between 4 and 10 degrees can have a significant effect (up to $\sim 10 \%$ ) on weight, as shown in Fig. 4. However, an angle steeper than 10 degrees does not have a major effect on strut weight. Northrop Grumman also conducted a detailed design and optimization for a very lightly loaded strut. This strut is required to support $1,183 \mathrm{lb}$ in compression and $1,443 \mathrm{lb}$ in tension. The lighter loading leads to a smaller diameter (approximately 2 inches) and much thinner wall thickness.

\section{Test Article Description}

To determine what concessions in design would have to be made to create flight hardware and to verify that fabricated struts meet design requirements, struts with construction as close as possible to the optimal designs were fabricated. All struts were fabricated using IM7-977-3 or IM7-8552 carbon epoxy and titanium end fittings. The wrapping method, curing method, tooling type, geometry, and end fitting concepts varied among the struts. Each strut consists of a composite tube body and a titanium end fitting on each end. A composite body-to-fitting joint in which a corrugated fitting where the fibers were wrapped around the corrugations and a step-lap joint fitting where the titanium was bonded to the composite were considered. Both contractors indicated that a more integrated strutfitting-node arrangement could lead to a lighter design for the lunar lander struts but this integration was not part of the current hardware effort.

Seven full-scale, optimum-design, test articles were fabricated. Fabrication of struts was required to address manufacturing concerns and evaluate imperfections. Boeing fabricated two highly loaded struts. Northrop Grumman fabricated three highly loaded struts and two lightly loaded struts. The design, manufacturing approach, and the final designs are presented in references 12-13.

Descriptions of the struts are shown in Table 1 for the tested manufacturing

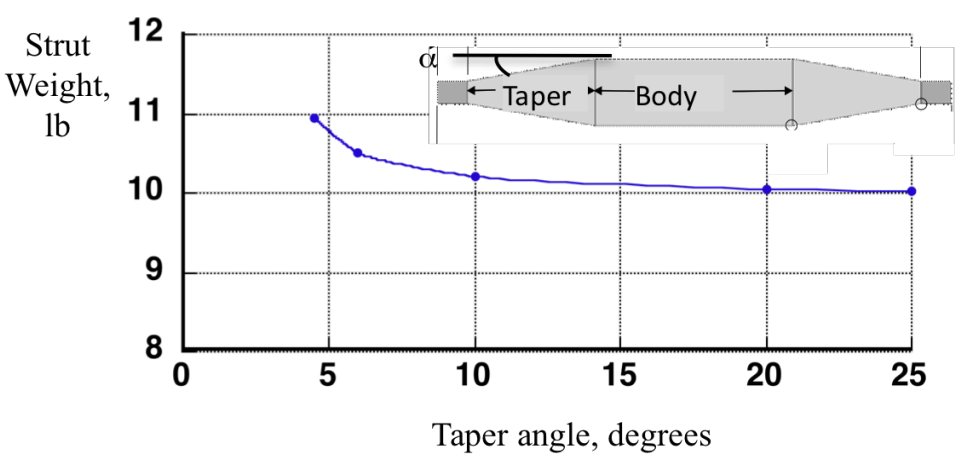

Figure 4. Effect taper on weight of most highly loaded strut. 
demonstration articles and the optimized struts. Photographs of representative test articles are shown in Fig. 5. Photographs of typical end fittings (prior to strut fabrication) are shown in Fig. 6. A sketch of a strut with the definitions of dimensions used in Table 1 is shown in Fig. 7.

Strut types are identified herein by their designer (B for Boeing and $\mathrm{N}$ for Northrop Grumman), their load level, ( $\mathrm{L}$ for lightly loaded struts and $\mathrm{H}$ for highly loaded struts) and the phase of the program during which they were constructed (phase I for the manufacturing demonstration articles or phase II for the optimized test articles). Additionally, a replicate number of 1,2, or 3 is added to differentiate individual struts within a type. Three struts fabricated as manufacturing demonstration articles (phase I) and seven struts optimized and designed as test articles (phase II) are included. These ten struts include four lightly loaded struts and six highly loaded struts which were fabricated and prepared for testing. Note that the fabricated test articles from phase II were 6 inches shorter than the optimized struts because the optimized struts included three inches on each end as node interface region while this distance was not included in the test articles.

\begin{tabular}{|c|c|c|c|c|c|c|c|}
\hline Strut type & $\begin{array}{c}\text { Strut } \\
\text { Length, } \\
\text { L, (in.) }\end{array}$ & $\begin{array}{l}\text { Central } \\
\text { Inner } \\
\text { Diameter, } \\
\mathrm{D}, \text { (in.) }\end{array}$ & $\begin{array}{c}\text { Central } \\
\text { Stacking } \\
\text { Sequence } \\
\% 0 / \% \pm 45 / \% 90\end{array}$ & $\begin{array}{l}\text { Composite } \\
\text { Untapered } \\
\text { Length, } \\
\text { b, (in.) }\end{array}$ & $\begin{array}{c}\text { Taper } \\
\text { Angle, } \\
\alpha\end{array}$ & $\begin{array}{l}\text { Fitting } \\
\text { Length, } \\
\text { f, (in.) }\end{array}$ & $\begin{array}{l}\text { Fitting } \\
\text { Concep } \\
\mathrm{t}^{*}\end{array}$ \\
\hline $\begin{array}{l}\text { B-L-I-1 } \\
\text { B-L-I-2 }\end{array}$ & 60.9 & 2.5 & $67 / 0 / 33$ & 42.5 & Body, $4^{\circ}$ & 2.04 & Cor. \\
\hline $\begin{array}{l}\text { N-L-II-1 } \\
\text { N-L-II-2 }\end{array}$ & 100.3 & 2.0 & $33 / 44 / 22$ & 92.7 & Body, $10^{\circ}$ & 1.25 & Cor. \\
\hline $\begin{array}{l}\text { B-H-II-1 } \\
\text { B-H-II-2 }\end{array}$ & 77.7 & 5.8 & $63 / 25 / 12$ & 61.0 & Fitting, $22^{\circ}$ & 8.35 & Bond \\
\hline $\begin{array}{l}\text { N-H-II-1 } \\
\text { N-H-II-2 } \\
\text { N-H-II-3 }\end{array}$ & 77.7 & 6.0 & $58 / 24 / 18$ & 50.7 & Body, $10^{\circ}$ & 2.94 & Cor. \\
\hline N-H-I-1 & 127.0 & 6.0 & $67 / 0 / 33$ & 73.7 & Body, $4^{\circ}$ & 2.94 & Cor. \\
\hline
\end{tabular}

* Cor.=corrugated; Bond=bonded

\section{A. Fabrication Method}

To fabricate a tube in which the center section has a larger diameter than either of the ends, either a fly-away or collapsible tool must be used to apply pressure to the inner surface. For a mass challenged spacecraft such as Altair, the added weight of fly-away tooling is not desired. Two types of removable tools, inflatable and plaster wash-out mandrels, were used in this study. In each case, the graphite layers were placed around the mandrel. In addition, when the inflatable mandrel was used, a clamshell arrangement was used on the outside of the strut to obtain a uniform thickness and smooth outer surface. The strut was cured and the interior plaster washed out with water or the bladder deflated and removed out through the end fitting. The wash-out mandrel was used for struts with the taper in the strut body, types B-L-I, N-L-II, N-H-II and N-H-I, all of which also use the corrugated fitting. The inflatable mandrel was used for struts B-H-II, which use the tapered end fitting. Details of the wash-out and inflatable mandrel manufacturing approaches are presented in reference 12 and 13 , respectively.

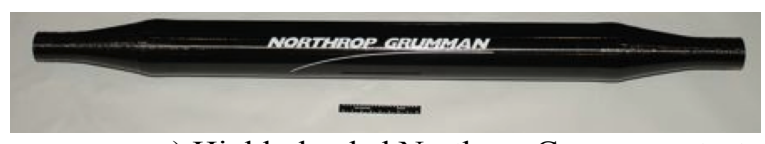

a) Highly loaded Northrop Grumman strut.

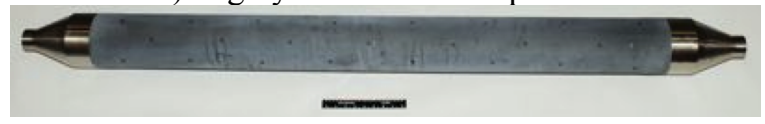

b) Highly loaded Boeing strut.

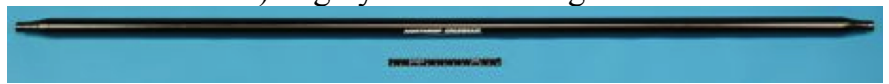

c) Lightly loaded Northrop Grumman strut.

Figure 5. Strut test articles.

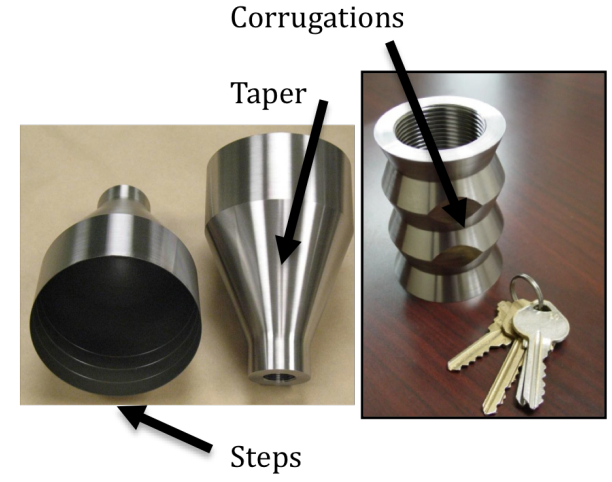

Figure 6. Titanium fittings for struts. 


\section{B. Composite Body}

Composite strut bodies for the lightly loaded struts contained 9 to 11 plies and minimum gage restrictions influenced their design. The composite strut bodies of the highly loaded struts were not influenced by minimum gage requirements and contained 16 to 18 plies.

Two types of lightly loaded struts were tested. B-L-I struts were actually designed as manufacturing demonstration articles but deemed of high enough quality to

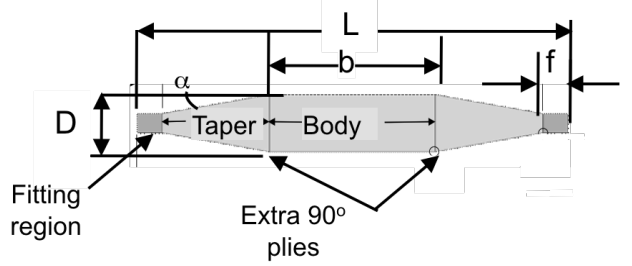

Figure 7. Reinforcement at taper edge. test and so were the shortest struts. Their design was not optimized and their stacking sequence $\left[90 / 0_{4} / \overline{90}\right]_{\mathrm{s}}$ contains only 0 - and 90-degree plies since those were simpler to fabricate. N-L-II struts were designed to meet the requirements for a lightly loaded Altair strut, and therefore, are the optimal design except for manufacturing considerations such as integral ply thickness. N-L-II struts contain a stacking sequence of $[90 / 0 / \underline{45 /} \overline{0}] \mathrm{s}$ and were designed to support 1,183 lb in compression and 1,443 lb in tension. All lightly loaded struts contained corrugated end fittings and a tapered strut body.

Three types of highly loaded struts were tested. B-H-II struts and N-H-II struts were designed as optimal for a highly loaded Altair strut. These struts were designed to support an axial compressive load of 107,585 $\mathrm{lb}$ and an axial tensile load of $60,182 \mathrm{lb}$. The stacking sequence for the Boeing struts was $\left[+45 / 0_{3} / 90 / 0_{2}\right]_{\mathrm{s}}$ and the Northrop Grumman struts was $\left[90 / 0_{2} / \pm 45 / 0_{3} / 90\right]_{s}$. These stacking sequences differ by only one ply, but there are more significant differences in the end fitting and taper region, as described below. Strut N-H-II-3 was fabricated with several intentional defects in the form of square Teflon inserts which were either 0.25 or 0.5 inches on a side. This strut was also subjected to low speed impact damage prior to loading. The remaining highly loaded strut, N-H-I-1, was fabricated as a manufacturing demonstration article but had a similar geometry and stacking sequence to an optimum strut design. It was designed to support a compressive load of 127,000 lb, and contained only 0 - and 90degree plies in the sequence $\left[90 / 0_{3} / 90 / 0_{3} / 90 / 0_{2} / 90 / 0_{2} / 90 / 0_{2} / 90\right]_{\mathrm{T}}$.

Several extra 90-degree plies were added to a small region of the N-L-II and N-H-II struts around the top of the taper, as shown in Fig. 7. These additional wraps were applied to reduce the stress concentration in that region without adding another ply to the whole length of the strut.

\section{End Fittings}

All fittings were made from titanium and threaded on the interior to match the test fixtures. Two types of fittings were used, as shown in Fig. 6. The corrugated fitting concept was used in eight struts of varying sizes and the bonded, tapered fitting was used in two struts.

The corrugated fitting concept has a series of grooves in the outer surface of the fitting which allow fibers to be placed into the groove and overwrapped with additional fibers which lock the layers in place. After the strut is cured, the fibers are locked into the grooves and the fitting cannot be removed even if the composite-to-fitting adhesive bond breaks. The only way to fail this joint is to break the fibers themselves. The geometry of the fitting is dependent upon the design load levels.

The bonded fitting concept uses a step-lap joint and adhesive to attach the titanium fitting to the carbon epoxy during cure. When the bonded fitting was used, the taper was in the fitting rather than in the composite, so a much steeper taper angle was achieved than could be fabricated in a composite body taper. However, a longer fitting was required to gain the necessary area for the bond to the composite body. In addition, since the test articles had to interface with the test facility, the threaded region of the fitting was longer in the bonded-fitting struts than might have been required for the lunar lander so the test articles may be slightly heavier than the comparable flight hardware would be.

\section{Geometric Imperfections and Weight}

Geometric imperfection evaluations of all fully-assembled struts were conducted either by the contractor who did the fabrication or by NASA. The only imperfection shape considered by NASA and discussed herein is a single half-wave deformation as shown in the sketch in Fig. 8. The imperfection amplitude as measured by NASA for each strut is shown in Table 2. In all cases, the measured imperfections are less than the imperfections allowed in the trade study which varied depending on length. The as-manufactured weight is also shown in Table 2. 
Figure 8. Shape of initial geometric imperfection.

Table 2. Measured Geometric Imperfections and Weight.

\begin{tabular}{lccc}
\hline \hline Strut ID & $\begin{array}{c}\text { Imperfection amplitude (in.) } \\
\text { NASA } \\
\text { measurement }\end{array}$ & $\begin{array}{c}\text { Contractor } \\
\text { measurement }\end{array}$ & Weight (lb) \\
\hline B-L-I-1 & 0.052 & $*$ & 3.6 \\
\hline B-L-I-2 & 0.046 & $*$ & 3.2 \\
\hline N-L-II-1 & 0.022 & 0.029 & 2.1 \\
\hline N-L-II-2 & 0.031 & 0.012 & 2.1 \\
\hline B-H-II-1 & 0.020 & 0.004 & 13.9 \\
\hline B-H-II-2 & 0.020 & 0.004 & 12.7 \\
\hline N-H-II-1 & 0.006 & 0.0043 & 11.6 \\
\hline N-H-II-2 & 0.034 & 0.225 & 13.0 \\
\hline N-H-II-3 & 0.025 & 0.023 & 12.1 \\
\hline N-H-I-1 & 0.072 & 0.102 & 26.3 \\
\hline \hline
\end{tabular}

\section{Analysis}

All fabricated struts were analyzed using finite element methods to determine the buckling load, strain distribution and failure load. Linear and nonlinear analyses using the finite element code ABAQUS ${ }^{16}$ were conducted. Linear analysis indicated that none of the struts would fail in tension in the composite body due to excessive strains at loads less than DUL. However, additional factors beyond strains had to be considered in compression. In each case an imperfection shape of one axial half-wave was assumed, as shown in Fig. 8, and the largest measured imperfection amplitude was used in a nonlinear analysis. A typical finite element model is shown in Fig. 9. Between 10,000 and 70,000 shell elements were used in each model. The properties of carbon-epoxy and titanium, as shown in Table 3, were used for the analysis. Pinned boundary conditions were implemented by adding multi-point constraints attaching each node around the cross section at the end of the strut to a single node for the load application point. These constraints are indicated by the pink connectors in Fig. 9. This load application point is located three to six inches from the end of the strut. Displacements and rotations are constrained at this point. This pinned condition is assumed to be conservative since the actual hardware would be more rigid than pinned (but not as rigid as clamped). Load-displacement and loadstrain relationships were predicted for all struts to guide testing. Detailed analyses of the fittings and the fittingcomposite interface were conducted during the design process and are presented in references 12 and 13, but are not presented herein. Detailed fitting analyses were not repeated by NASA.

\section{Specimen Preparation and Testing}

Between 20 and 60 strain gages were attached to the outer surface of each test article prior to testing. Strain gages were applied at

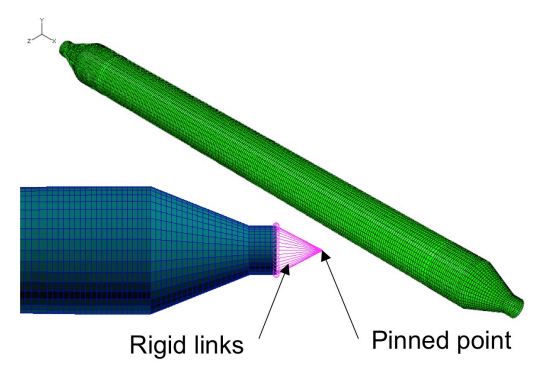

Figure 9. Typical finite element model.

Table 3. Assumed Material Properties

\begin{tabular}{llll}
\hline \hline & $\begin{array}{c}\text { Carbon- } \\
\text { epoxy } \\
\text { Compression }\end{array}$ & $\begin{array}{c}\text { Carbon- } \\
\text { epoxy } \\
\text { Tension }\end{array}$ & $\begin{array}{c}\text { Titanium } \\
\text { Tension and } \\
\text { Compression }\end{array}$ \\
\hline $\mathrm{E}_{11}, \mathrm{psi}$ & $21,400,000$ & $24,500,000$ & $16,000,000$ \\
\hline $\mathrm{E}_{22}, \mathrm{psi}$ & $1,460,000$ & $1,260,000$ & $16,000,000$ \\
\hline $\mathrm{G}_{12}, \mathrm{psi}$ & 690,000 & 690,000 & $6,060,610$ \\
\hline $\mathrm{v}_{12}$ & 0.3 & 0.3 & 0.32 \\
\hline \hline
\end{tabular}


select locations to monitor stress concentrations and buckling behavior. A typical strain gage pattern is shown in Fig. 10. In addition, one section of each specimen was painted with a black and white speckle pattern so that a vision image correlation (VIC) system could be used to monitor full-field displacements and strains over the taper and fitting region on one end of each strut, as shown for specimen N-H-II-1 in Fig. 11.

Each test article was mounted vertically between fixtures. The load was applied through the threaded end fittings. Photographs of the test arrangements are shown in Fig. 11. In each case, the strut fitting at the top was attached to brackets which attached to the test wall. The test fixtures at the top and bottom were designed to allow for rotation of the strut in any direction during the testing, as described in reference 14. For the highly loaded struts, the fitting at the bottom of the strut was attached to a 225-kip load cell, which was attached to a 225-kip actuator, which was attached to the test wall and supported by the floor. For the lightly loaded struts, the fitting at the bottom was attached to a 50-kip load cell for struts of type B-L-I or a 10-kip load cell for struts of type N-L-II. The 225-kip actuator was used for the type B-L-I struts, but a hand pump was used to apply load to the very lightly loaded N-L-II struts. More details of the testing arrangement and set-up are presented in reference 14.

The initial intent was to load all struts in tension to Design Limit Load (DLL) and in compression to failure. In all cases, DLL is $71 \%$ of DUL. However, strut behavior necessitated changes in that sequence which will be described with the results for each type of strut. For all struts except N-L-II type struts, an end displacement was applied at the rate of $0.001 \mathrm{in} / \mathrm{sec}$ in either tension or compression until the desired load or failure was reached. Pristine struts of types N-H-I, $\mathrm{N}-\mathrm{H}-\mathrm{II}$ and B-L-I were loaded to DLL in tension, then to the largest load it could support in compression. Strut B-H-I-1 was loaded to DLL in tension and then to failure in compression but strut B-H-I-2 was loaded only to failure in compression. Strut NH-II-3 had planned defects and was only loaded in compression. Strut N-L-II-1 was loaded to two times its DUL in tension and then to the largest load it could support in compression. Strut NL-II-2 was loaded to the largest load it could support in compression.

The behavior of each test article was monitored by numerous linear variable displacement transducers (LVDT). Three LVDTs placed at 0,120 , and 240 degrees around the circumference measured axial displacement of the entire strut; one LVDT measured the axial displacement of the constant-cross section region of the composite body, and two LVDTs at 0 and 90 degrees around the circumference measured radial motion at the lengthwise center of the strut. Strain gage and LVDT reading were recorded at the rate of $1 \mathrm{~Hz}$ and VIC images were recorded at $1 \mathrm{~Hz}$.

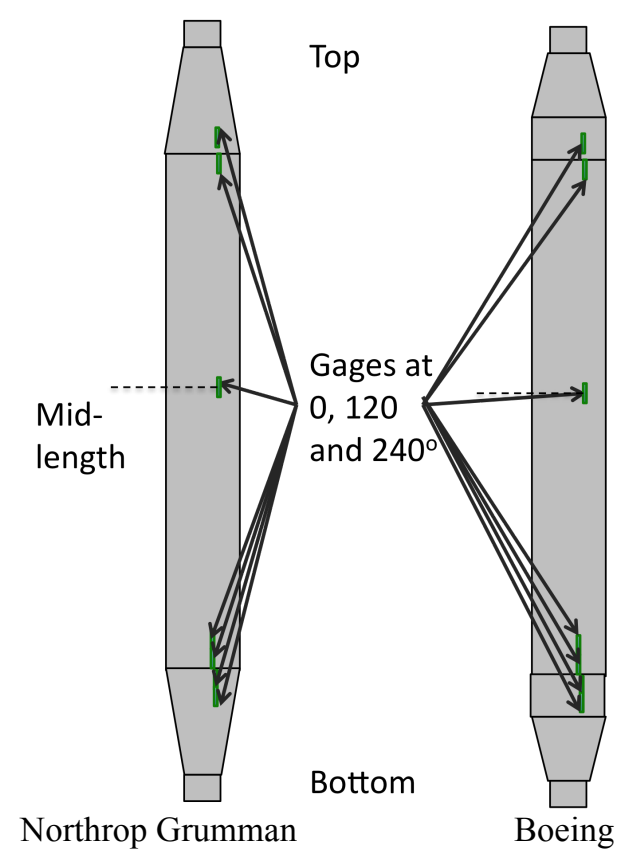

Figure 10. Typical strain gage pattern.

\section{Results and Discussion}

A summary of the displacements, strains and failure modes for the ten test articles is presented herein, and these results are compared to analytical predictions. Predicted and experimental failure loads are shown in Table 4 for all tested struts. A larger selection of strains and displacements for the optimized test articles, types N-H-II, B-H-II, and N-L-II, is presented in reference 15 . 

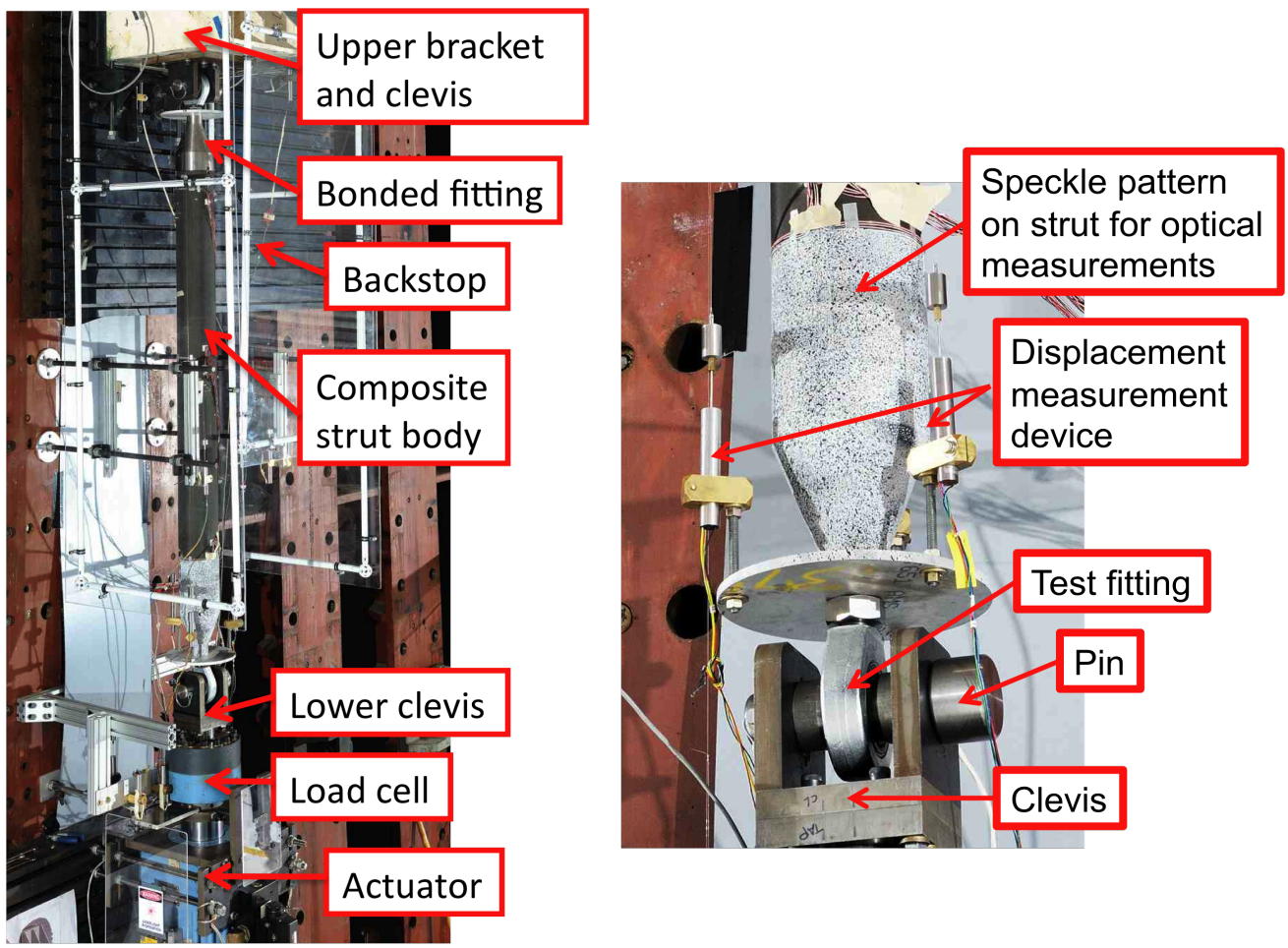

Figure 11. Strut B-H-II-1 in the test fixture prior to testing.

Table 4. Analytical Predictions and Experimental Maximum Loads.

\begin{tabular}{lcccccc}
\hline \hline $\begin{array}{l}\text { Strut } \\
\text { type }\end{array}$ & $\begin{array}{c}\text { Compressive } \\
\text { DUL (lb) }\end{array}$ & $\begin{array}{c}\text { Tensile } \\
\text { DUL (lb) }\end{array}$ & $\begin{array}{c}\text { Predicted } \\
\text { Bifurcation } \\
\text { Buckling Load } \\
(\mathrm{lb})\end{array}$ & $\begin{array}{c}\text { Predicted } \\
\text { Maximum } \\
\text { Compressive } \\
\text { Load (lb) }\end{array}$ & $\begin{array}{c}\text { Assumed } \\
\text { Imperfection } \\
\text { Amplitude } \\
\text { (in.) }\end{array}$ & $\begin{array}{c}\text { Experimental } \\
\text { Maximum } \\
\text { Load (lb) }\end{array}$ \\
\hline B-L-I & $*$ & $*$ & 27,800 & 22,600 & 0.049 & $\begin{array}{c}27,410 \text { and } \\
23,260\end{array}$ \\
\hline N-L-II & 1,183 & 1,443 & 1,290 & 1,260 & 0.029 & $\begin{array}{c}2180 \text { and } \\
1980\end{array}$ \\
\hline B-H-II & 107,585 & 60,182 & 121,600 & 113,800 & 0.020 & $\begin{array}{c}43,500 \text { and } \\
79,900\end{array}$ \\
\hline N-H-II & 107,585 & 60,182 & 141,700 & 130,000 & 0.043 & 119,300 and \\
& & & & & & 121,700 \\
\hline N-H-I & 110,000 & $*$ & 159,900 & 142,600 & 0.072 & 103,600 \\
\hline \hline
\end{tabular}

* Manufacturing demonstration article, load was not a design parameter

\section{A. Loads and Displacements}

\section{Lightly loaded struts}

The lightly loaded struts all withstood the applied tensile and compressive loading with little or no visible damage but buckled at their maximum loading. Struts with design B-L-I sustained a tensile load equal to 70 percent of the compressive DUL then were loaded to the maximum load in compression. Buckling loads exceeded the predicted loads for struts B-L-I-1 and B-L-I-2 by approximately 22 percent and 3 percent, respectively. Struts with design NL-II were designed to meet much lower loading requirements, and the required tensile load is greater than the required compressive load. Strut N-L-II-1 was loaded to twice its DUL in tension, then loaded in compression to its 
maximum (buckling) load. Its maximum load was approximately twice the predicted maximum compressive load. Strut N-L-II-2 was not preloaded in tension but only loaded in compression and supported approximately 1.6 times its predicted maximum load in compression. All of the lightly loaded struts supported more than DUL in compression.

Measured axial displacements for compressive loading for specimens B-L-I-1 and B-L-I-2 are shown in red and blue, respectively, in Fig. 12. Measured axial shortening in the entire strut length at three locations around the circumference are shown as dashed lines of different dash lengths. Analytical predictions are shown as solid back lines. The strut motion is not uniform around the circumference, however, the measurements are repeatable from one strut to the next. Averages of the three test measurements are shown as solid green lines for the B-L-I struts in Fig. 12 and for the N-L-II struts in Fig. 13. These averages agree well with the analytical predictions for initial stiffness. The struts buckled at a greater load than predicted by the analysis, indicating that the influence of the initial geometric imperfection may not have been as significant as anticipated, or that there may have been friction or other behavior at the ends in the fixtures to invalidate the "pinned" assumption at the ends.

\section{Highly loaded struts}

All highly loaded pristine struts with corrugated fittings withstood their tensile DLL prior to compressive loading. The highly loaded pristine phase II corrugated-fitting struts withstood 110 and $112 \%$ of DUL in compression prior to failure in the fitting region. The highly loaded phase I corrugated fitting strut withstood $94 \%$ of its compressive DUL prior to failure. However, the highly loaded bonded-fitting struts did not support the required loads. One strut exhibited debonds in the fitting-composite joint at approximately $30,000 \mathrm{lb}$ in tension, less than the tensile DLL in its first loading. The other bonded-fitting strut was not initially loaded in tension but failed catastrophically at the fitting-composite joint at approximately $70 \%$ of its compressive DUL.

Measured axial displacements for the highly loaded struts are shown in Figs. 14-16. Displacements for struts B-H-II-1 and B-H-II-2 are shown in Fig. 14 while displacements for struts N-H-II-1 and N-H-II-2, are shown in Fig. 15. Results for strut N-H-II-3 are presented in reference 15. Displacements for N-H-I-1 are shown in Fig. 16. Measured axial displacement for the entire strut length at three locations around the circumference are shown as dashed lines. Analytical predictions are shown as solid lines. Good agreement between test and analysis can be seen for the initial stiffness for all highly loaded struts under both tensile and compressive loadings.

The first bonded fitting strut tested, B-H-II-1, sustained damage in the initial tensile loading to DLL so it only sustained approximately $43,000 \mathrm{lb}$ in the subsequent compressive loading. In order to start with a pristine strut for compression loading, the second bonded-fitting strut, B-H-II-2, was not initially loaded in tension. Even without the preload, the strut failed in compression at $80,000 \mathrm{lb}$, or approximately DLL. Little warning

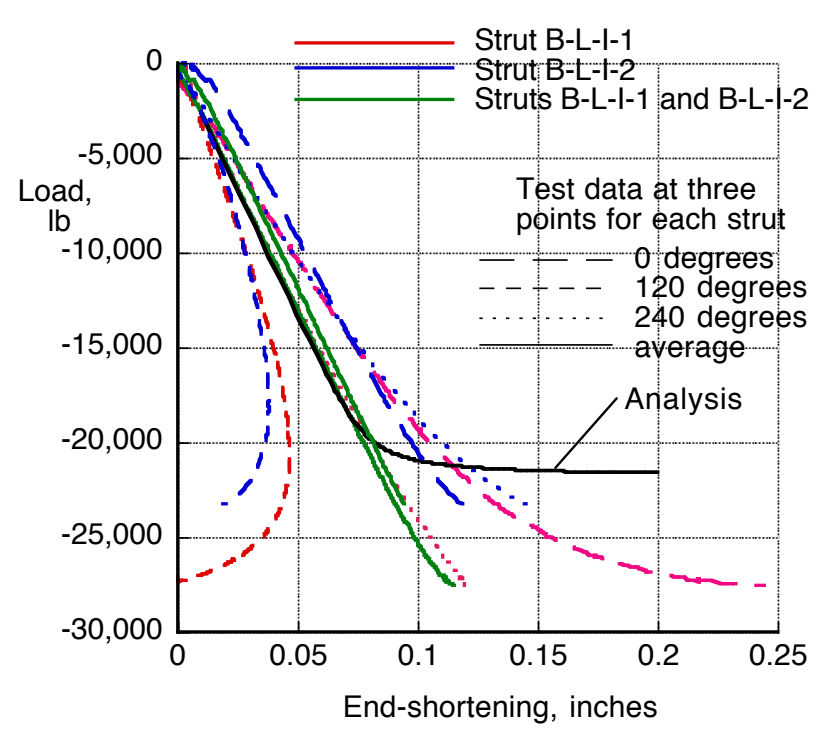

Figure 12. Axial displacement for struts of type B-L-I.

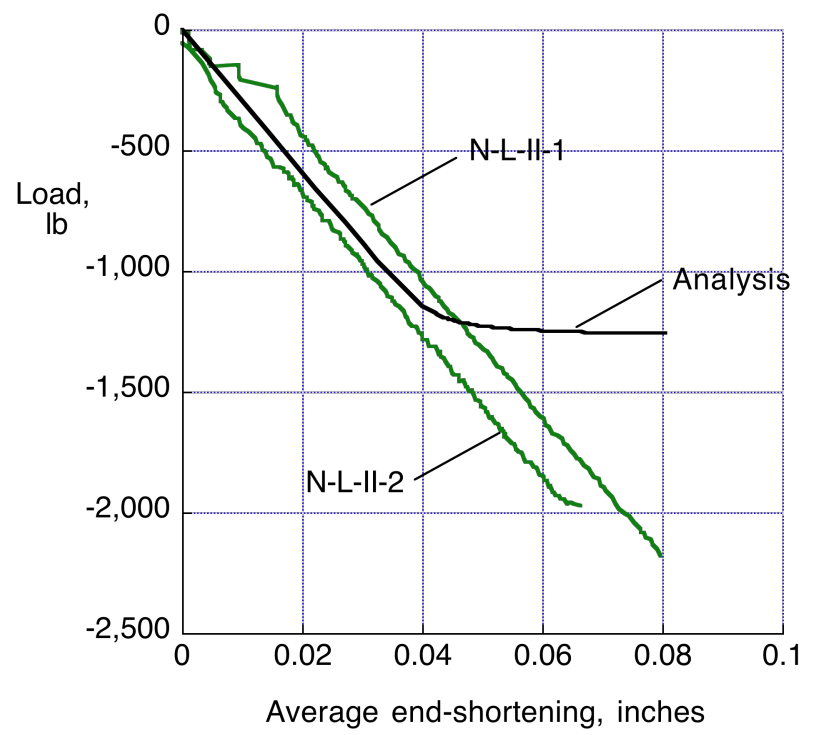

Figure 13. Axial displacement for struts of type N-L-II. 
of impending failure was evident by any measurement during the test. The highly loaded struts displayed little nonlinear or buckling behavior prior to DUL.

\section{B. Strain}

\section{Lightly loaded struts}

Measured axial strains at the midlength location for specimens B-L-I-1 and B-L-I-2 are shown in red and blue, respectively, in Fig. 17. Similarly, midlength axial strains for specimens N-L-II-1 and N-L-II-2 are shown in red and blue, respectively, in Fig. 18. Measured axial strains at three locations around the circumference are shown as three dashed lines of different dash lengths in Figs. 17 and 18. The average of these strain measurements for each strut are shown as the green solid lines. While the strains are not uniform around the circumference and nonlinearity is evident in the individual results, the average strain is linear until just before the maximum load is reached and the two struts of each type agree with each other. The strains at the taper region show similar behavior as the strains in the center of the strut body (not shown).

\section{Highly loaded struts}

Measured axial strains for the highly loaded struts are shown in Figs. 19-23. Strains at the midlength location for specimens B-H-II-1 and B-H-II-2, are shown in red and blue, respectively, in Fig. 19 while midlength axial strains for specimens N-H-II-1 and N-H-II-2 are shown in red and blue, respectively, in Fig. 20. Measured axial strains at three locations around the circumference are shown as dashed lines of different dash lengths in Figs. 19 and 20.

Measured axial strains at the fitting-tocomposite interface region for specimens B-H-II1 are shown in Fig. 21 for the tensile loading and Fig. 22 for the subsequent compressive loading of B-H-II-I. The full-field axial strain for the lower end of strut B-H-II-1 at approximately $43,835 \mathrm{lb}$ tensile load and of strut B-H-II-2 at approximately $79,800 \mathrm{lb}$ compressive load are also shown in Figs. 21 and 22, respectively.

Axial gages were located on the exterior surface of the composite body and on the exterior surface of the titanium fitting at three locations around the circumference. Strains on the composite are shown in red and strains on the titanium surface are shown in blue. The discontinuities in the measured strain under tensile loading are believed to indicate damage to the bond between the composite steps and the titanium fitting. Damage to the bond began to initiate at a load significantly less than DLL in the tensile loading. The appearance of these discontinuities in all three gages indicates that there was damage in the bond all the way around the circumference. This damage was already present prior to compressive loading of strut B-H-II-1. No such discontinuities are seen in the compressive loading of strut B-H-II-2. The surface strains in both loadings are between 0 and 0.003 , indicating that there are no excessive surface strains in the fitting or the composite. 


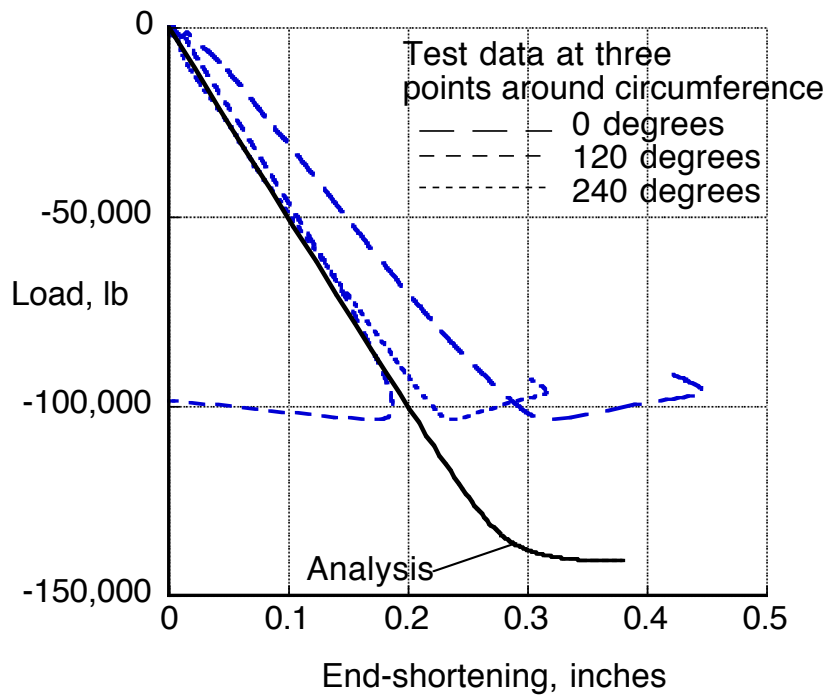

Figure 16. Axial displacement for strut N-H-I-1.

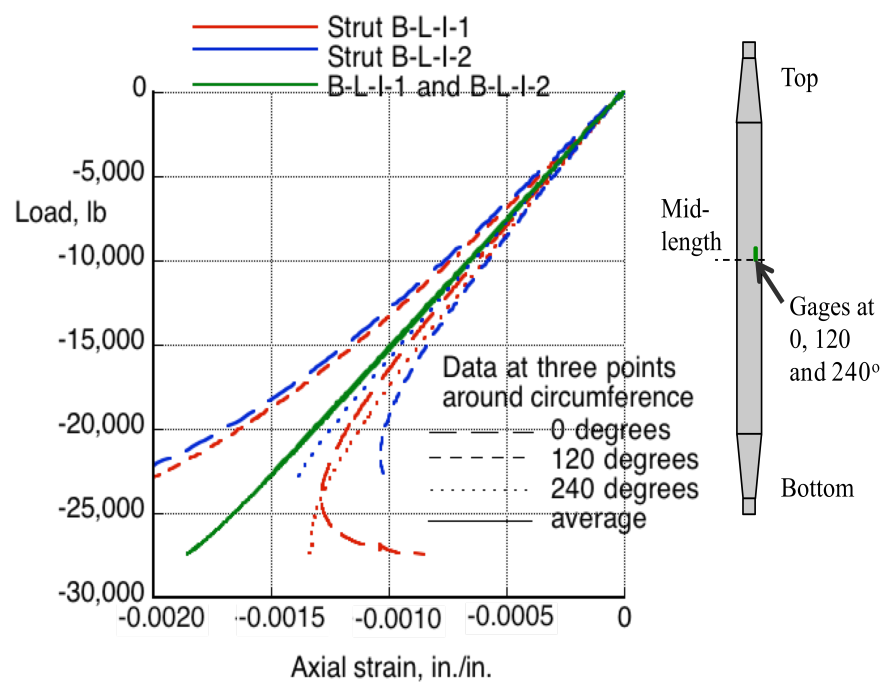

Figure 17. Centerline axial strain for struts of type B-L-I.

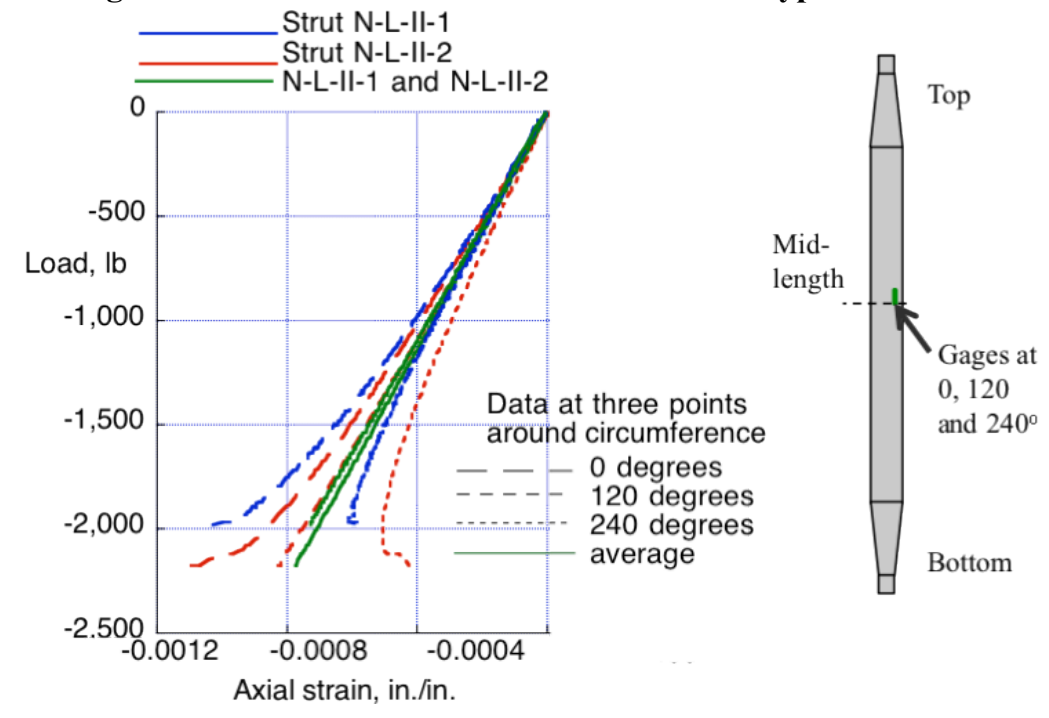

Figure 18. Centerline axial strain for struts of type N-L-II. 


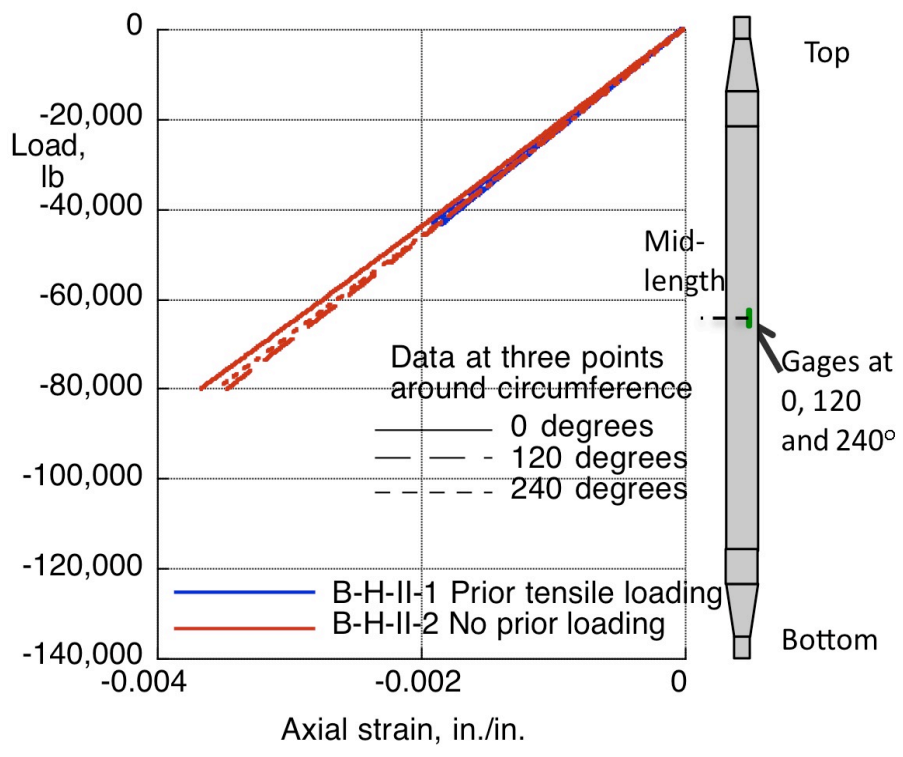

Figure 19. Axial strain for strut body for struts of type B-H-II.

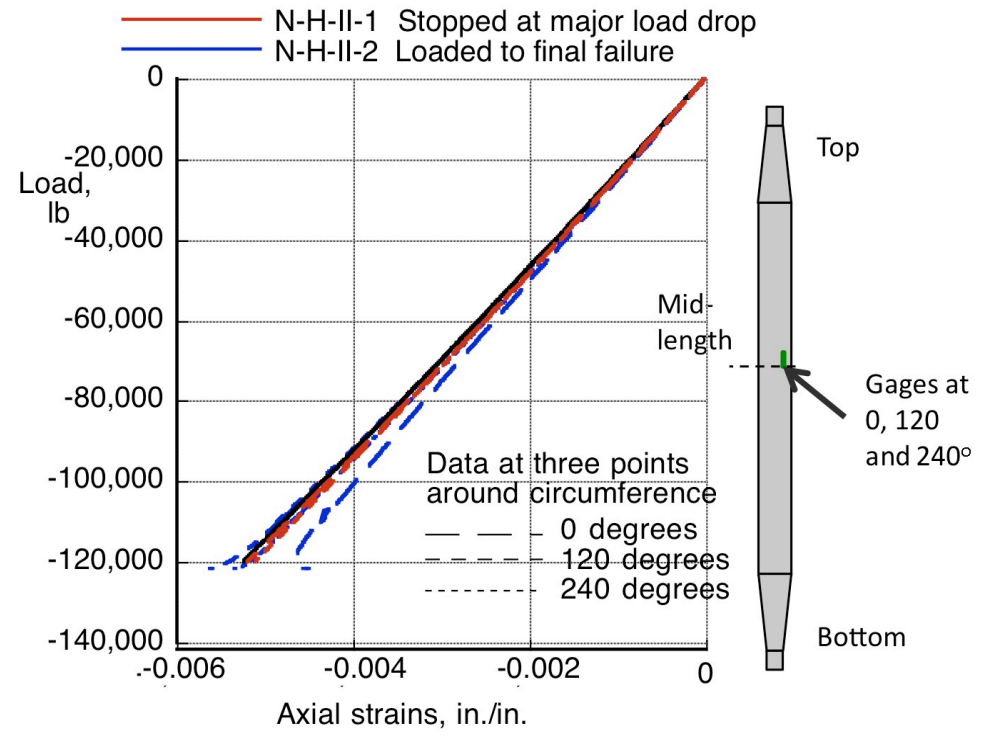

Figure 20. Axial strain for strut body for struts of type N-H-II. 


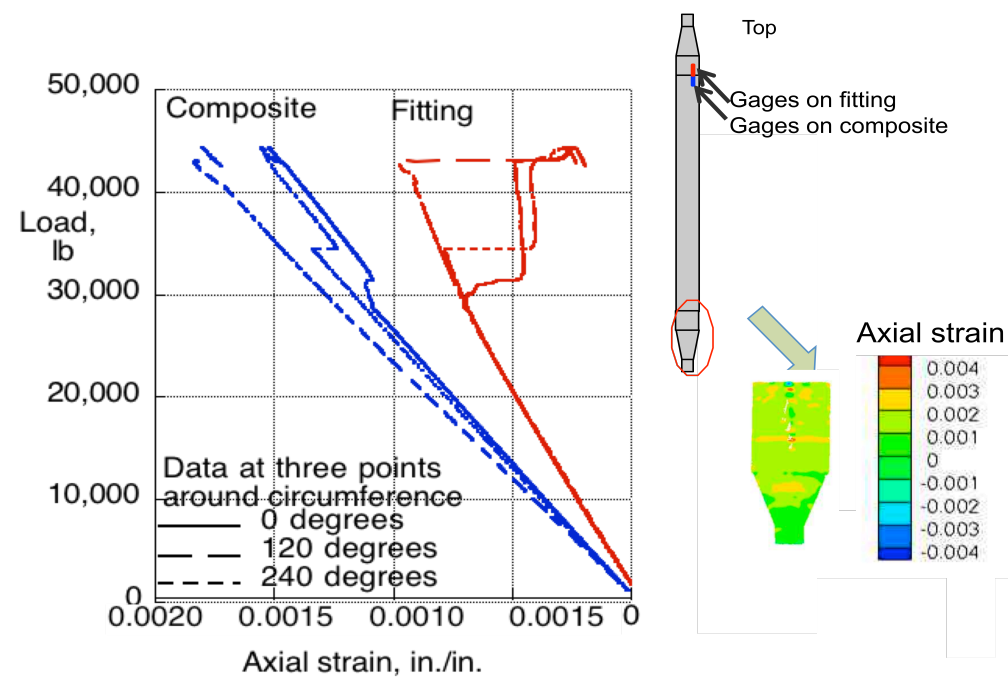

Figure 21. Axial strain for interface location for strut B-H-II-1 loaded in tension with full field strains at $43,835 \mathrm{lb}$.

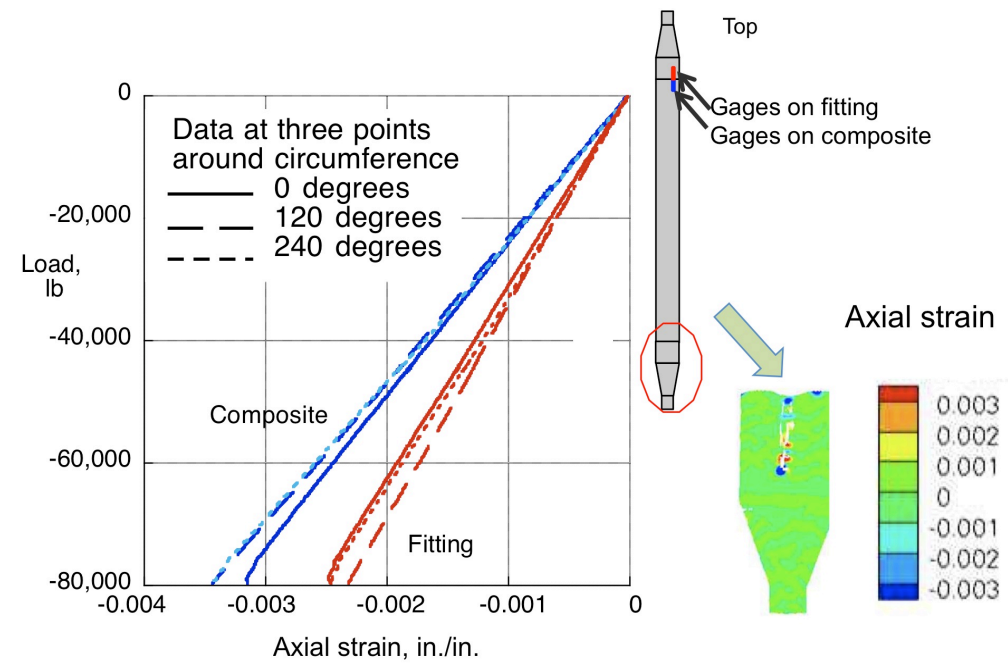

Figure 22. Axial strain for interface location for strut B-H-II-2 loaded in compression with full field strains at 79,800 lb.

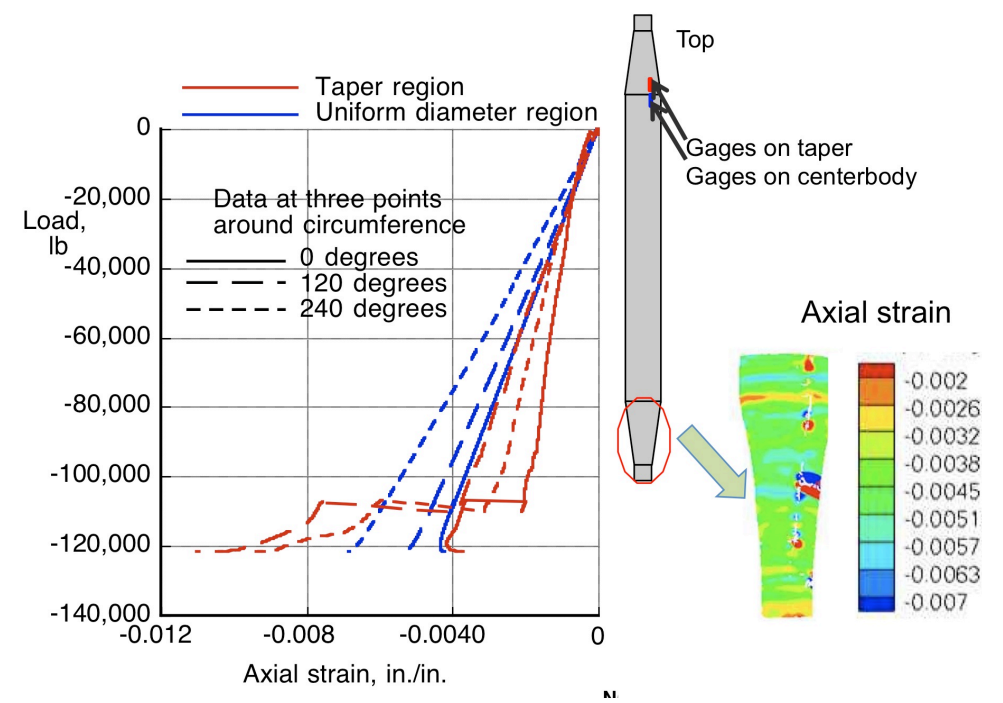

Figure 23. Axial strain at taper for struts of type N-H-II with full field strains at 117,444 lb. 
Measured axial strains at the transition from the center body diameter to the smaller end diameter for specimens of type N-H-II are shown in Fig. 23. The gages at the larger diameter location remain linear until immediately prior to failure. The gages on the taper and closer to the end of the strut show discontinuities indicating damage in the fitting region starting at approximately $110,000 \mathrm{lb}$. The full-field axial strains at a load of $117,444 \mathrm{lb}$ show bands of strains which are related to the corrugations in the fitting.

\section{Failure}

Visual inspection of struts after the maximum loading test did not always reveal a failure location. Photographs of failed highly loaded specimens are shown in Figs. 24 and 25. Both struts with the bonded end fitting failed the composite-to-fitting joint as shown in Fig. 24. Further evaluation of the bonded struts was not conducted to determine if the premature failures were due to design or construction. Visible failures in the corrugated fitting struts were generally of the kind shown in figure 25 and restricted to the fitting region. The corrugated fitting design does not rely on the adhesive bond, so there is no evidence of the condition of the bond to the fitting. The fibers held the strut together until loading reached the compressive design ultimate load in each case. Lightly loaded specimens buckled when they reached their maximum load and left little evidence of fiber damage after loading was removed. Photographs of strut N-L-II-2 showing buckling at maximum loading are shown in Fig. 26. NDE was not conducted after testing to find any damage.

The structural efficiency of each strut design is shown in Fig. 27. Structural efficiency is shown as the maximum compressive load a strut could support divided by its measured weight. Only struts which began their compressive loading with no damage are included. By this measure, the most structurally efficient struts are the highly loaded corrugated-fitting struts, N-II-H.

\section{Concluding Remarks}

Trade studies involving 30 strut types with loads and lengths appropriate for the Altair lunar lander were conducted by three industry partners. Minimum weight designs were determined for the most highly loaded of the 30 strut types and samples of these struts were fabricated.

The most significant conclusions of the trade studies are that: 1) Numerous behaviors and failure mechanisms including local buckling, global buckling, and stress concentrations must be considered in the design process; 2) Fitting weight can be a significant portion of strut weight so the entire assembly must be optimized to obtain the minimum weight design for the vehicle; 3) Strut diameter and taper have a significant effect on weight; 4) An intermediate modulus fiber such as IM7 provides the minimum weight if one fiber is used for all struts; 5) while uniaxial loading implies a 0 -degree dominated stacking sequence, the presence of \pm 45 -degree plies does not impose a weight penalty; 6) Local reinforcement at the taper edge can result in a lower weight design; and that 7) When considering the entire group of struts, the composite struts weigh approximately $30 \%$ less than the equivalent aluminum-lithium struts.

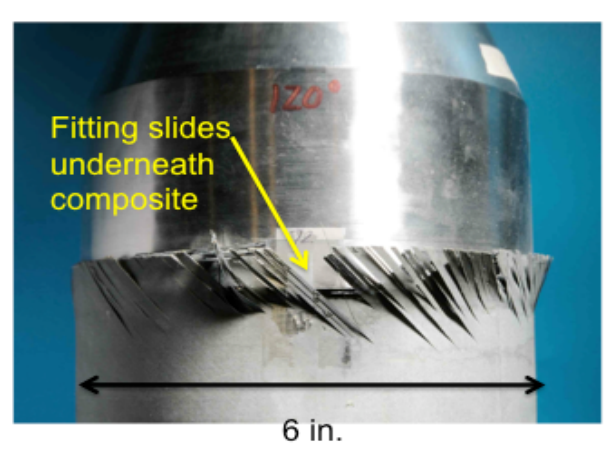

Figure 24. Failure of strut with bonded fitting.

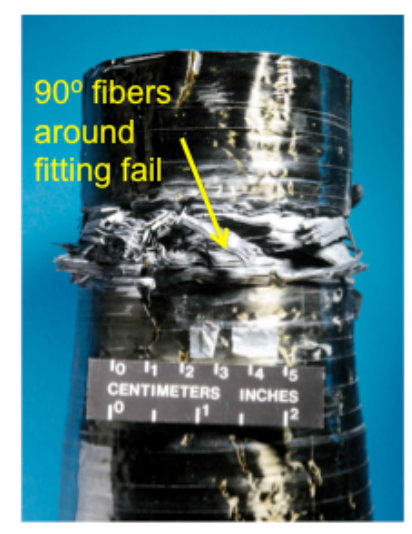

Figure 25. Failure of strut with corrugated end fitting. 

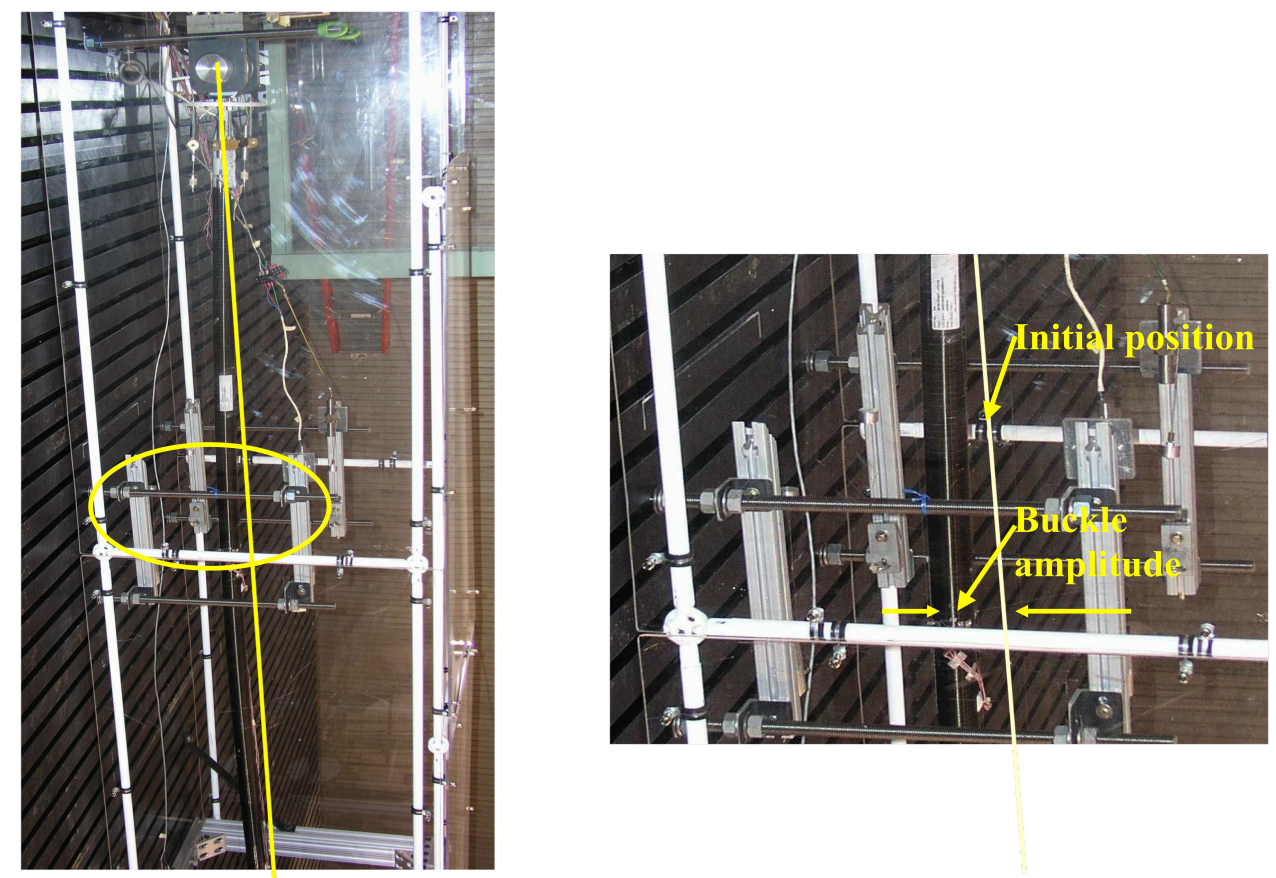

Figure 26. Buckling of specimen N-L-II-2.

Struts fabricated using the corrugated-fitting concept met the required compressive loading for highly and lightly loaded struts. Conversely, struts fabricated using a bondedfitting concept failed at significantly lower loads than the design requirement. The corrugated-fitting struts sustained Design Ultimate Load and eventually failed in the taper region, fitting region or buckled with no actual material failure. The bonded-fitting struts failed the adhesive bond between the titanium and composite. Of the struts evaluated in this study, only the corrugated-fitting struts meet the requirements defined by the Altair lunar lander project. Further study of struts with bonded fittings could result in designs that would support the required loading but no such work was done in this study.

Based on the trade study and experimental results, highly loaded carbon-epoxy tapered struts provide a lighterweight alternative to aluminum lithium for aircraft or spacecraft structures. Further optimization and an expanded set of requirements would be needed to conduct further evaluations. In any further studies, the fitting and fitting-to-composite interface must be a significant element of the evaluation, particularly for highly loaded applications. Additionally, truss assemblies including nodes must be evaluated.

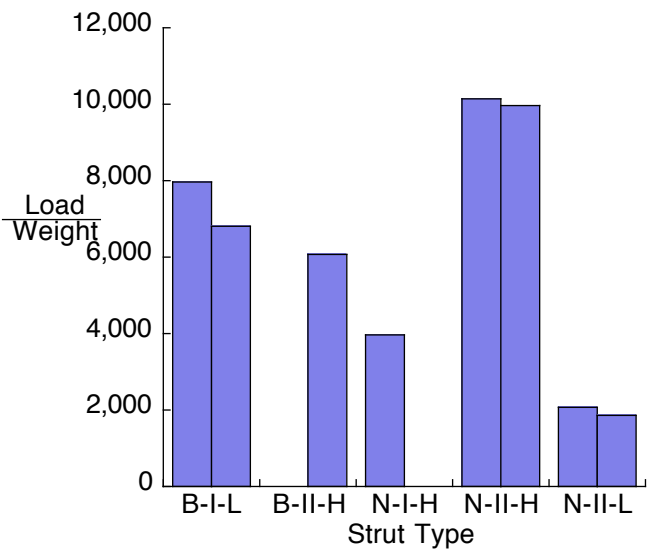

Figure 27. Structural efficiency of tested struts. 


\section{References}

${ }^{1}$ Wagner, H., "Remarks on Airplane Struts and Girders under Compressive and Bending Stresses. Index Values." NACA TM 500. 1929.

${ }^{2}$ Dow, N. F., and Hickman, W. A., "Design Charts for Flat Compression Panels Having Longitudinal Extruded Y-Section Stiffeners and Comparison with Panels Having Formed Z-Section Stiffeners,” NACA NT 1389, 1947.

${ }^{3}$ Williams, J., Anderson, M., Rhodes, M., Starnes, J., and Stroud, J., "Recent Developments in the Design, Testing and Impact-Damage Tolerance of Stiffened Composite Panels," NASA TM 80077, 1979.

${ }^{4}$ Williams, J. G., and Stein, M., "Buckling Behavior and Structural Efficiency of Open-Section Stiffened Composite Compression Panels." AIAA Journal, Vol. 14, No. 11, 1976, pp. 1618-1626.

${ }^{5}$ Williams, J. G., and Mikulas, M. M., Jr. "Analytical and Experimental Study of Structurally Efficient Composite HatStiffened Panels. Presented at the ASME/AIAA SAE $16^{\text {th }}$ Structures, Structural Dynamics and Materials Conference, Denver Colorado, 1995. AIAA Paper No. 75-754.

${ }^{6}$ Dow, N. F., and Rosen, B. W., "Structural Efficiency of Orthotropic Cylindrical Shells Subjected to Axial Compression," AIAA Journal, Vol. 4, No 3, 1966, pp. 481-485.

${ }^{7}$ Haynie, W. T., and Hilburger, M., "Comparison of Methods to Predict Lower Bound Buckling Loads of Cylinders Under Axial Compression," Presented at the $51^{\text {st }}$ AIAA/ASME/ASCE/AHS/ASC Structures, Structural Dynamics, and Materials Conference, 2010, Orlando, Florida, AIAA Paper No 2010-2532.

${ }^{8}$ Collins, T. and Nienaber, T., "Design and Analysis Cycle III Structures and Mechanisms Design Summary" Altair

Structures and Mechanisms Subsystems, Presented at Johnson Space Center, Houston, TX, June 25, 1010.

${ }^{9}$ Brewster, Jebediah, Design of Structurally Efficient Tapered Struts, NASA CR 2009-8393, December 2009.

${ }^{10}$ Messinger, R., "Design of Structurally Efficient Tapered Struts," NASA CR 2010-216698, 2010.

${ }^{11}$ Deo, R., Benner, H., Dawson, V., Olason, E., and Harrison, R. "Design of Structurally Efficient Tapered Struts (SETS)." NASA CR 2010-216699.

${ }^{12}$ Messinger, R., "Design and Manufacturer of Structurally Efficient Composite Struts - Concept 1," Final Report for NASA contract NAS NAS1-NNL04AA11B Task NNL09AC35T, 2009.

${ }^{13}$ Pires, K., Benner, H., Deo, R., Grover, R., Palm, T., McLaughlin, M., Olason, E., Lucking, R., and Collier, C., "Design and Manufacturer of Structurally Efficient Composite Struts - Concept 2," Final report for NASA contract NAS NAS1NNL04AA13B Task NNL09AC36T, 2010.

${ }^{14} \mathrm{Wu}$, K. C., Phelps, J, McKenney, M., and Jegley, D., "Highly Loaded Composite Strut Test Development," at 52 AIAA/ASME/ASCE/AHS/ASC Structures, Structural Dynamics and Materials Conference, Denver CO, 2011 (to be presented).

${ }^{15}$ Jegley, D., Wu, K. C., Phelps, J, McKenney, M., Oremont, L., and Barnard, A., "Evaluation of Long Composite Struts," NASA TM, 2011 (to be published).

${ }^{16}$ ABAQUS version 6.9 EF1 On-line Documentation, ABAQUS Analysis User's Manual, Dassault Systemes Simulia Corp., Providence, RI, 2009. 